\title{
ROLE OF COMMUNITY-LED PLANNING FOR EFFECTIVE WIDE-AREA REGIONAL EVACUATION
}

\author{
TAKEYASU SUZUKI \\ Disaster and Environmentally Sustainable Administration Research Center, University of Yamanashi, Japan
}

\begin{abstract}
Abnormal weather caused by global warming has brought about unprecedented torrential rain, causing heavy rain disasters in various parts of Japan. Since recent river flooding caused inundation damage over a wide area, area-wide evacuation, that is, evacuation to a safe place beyond municipalities' boundaries is necessary to save lives. This paper first introduces the community disaster management planning system that was established in Japan in the wake of the Great East Japan Earthquake in 2011. Next, the necessity of wide-area evacuation that has become apparent due to the recent flooding of large-scale rivers and a few problems that have arisen in the government-led wide-area evacuation plan are introduced, because residents' concrete evacuation behaviour was not sufficiently reflected. The author discusses efforts of a community in the Kofu basin, Yamanashi Prefecture which has been working to formulate a community disaster management plan for wide-area evacuation and city and prefectural efforts that support this district. The author also describes the risk communication that was undertaken to clarify the role of central ministries, local governments and community residents in the formulation of wide-area evacuation plans. Finally in wide-area evacuation drills, planned and conducted by the community in 2020 during the COVID-19 pandemic, the community disaster management plan is further reviewed. In this article, the author addresses how such a community-led wide-area evacuation plan is indispensable for administrations' effective wide-area evacuation planning.

Keywords: risk communication, wide-area evacuation, community-led, community disaster management plan, evacuation drill, flood countermeasures.
\end{abstract}

\section{INTRODUCTION}

Extreme weather caused by global warming has resulted in increased intensity and numbers of heavy rain disasters worldwide. In Japan since 2014, for example, four to six typhoons have made annual landfall, doubling from 2.7, the average number of landings during the 30year period from 1981 to 2010 [1]. The highest rainfall in the history of observations has been updated nationwide, and use of past meteorological observation data to predict stochastic disaster events is no longer meaningful. In Japan, river management is determined based on degree of importance, and river facilities are designed based on design discharge. However, compared to flood control in Europe and the United States, Japan still has room for improvement in flood control safety and achievement [2].

Considering physical measures' limitations in strengthening river facilities to protect against floods (i.e., measures to protect), a drastic change was made to more intangible measures to protect lives by evacuation through amendment of the Flood Control Law in 2005 (i.e., measures to evacuate) [3]. However, these measures cannot now match the level of abnormal weather events because floods due to the greatest expected rainfall have actually occurred and social systems have collapsed. Damage caused by the 2018 heavy rainfall disaster in western Japan and the 2019 typhoon No. 19 has indicated the need to build resilient cities able to recover quickly from flooding. Therefore, in addition to "protecting" and "evacuating", developing cities that can escape or overcome floods and minimize damage (i.e., measures to "dodge" flood hazards) is crucial. Thus, the countermeasure, "dodge", 
which involves building cities that can maintain their function and minimize damage to inhabitants' property and lives, is essential for urban sustainability [4].

The southern Kofu basin, Yamanashi Prefecture, Japan, is a region with high risk of flood damage. The region has no safe upland, and severe inundation during heavy rainfall is expected. Furthermore, a new station for the Linear Motor Chuo Shinkansen Line is planned for construction as a center for the neighbourhood's urban development. To build a sustainable, flood-resilient city in such a hazardous area, the author established an urban development study group [5], which has proposed a future sustainable Kofu basin under knowledge brokers' initiative and with experts' cooperation. The group applied the concept of sustainable cities presented by the author and proposed building detention/retention basins, a nature museum, stay-type leisure facilities, raised ground created by banking, artificial land and high-rise buildings, and a transportation network - thus forming constituent elements for a sustainable, flood-resilient Kofu basin [4].

However, sustainable city development requires sufficient discussion and timeconsuming consensus building. After that, residential land will be constructed by raising ground, and for residents, moving to safe from hazardous areas will take 20 or 30 years. Therefore, protecting lives from flood damage is essential - most likely via wide-area evacuation - that is, evacuation to a safe place beyond municipalities' boundaries - until residences' relocation to safe areas is completed.

Here, the author discusses efforts of the Riverside District, Chuo City in the Kofu basin, which has been working to formulate a community flood plan [6], [7]. Via risk communication conducted by the author, this article introduces city and prefectural efforts that support this district. As a result of wide-area evacuation drills, planned and conducted in 2020 during the COVID-19 pandemic, the community disaster management plan was further reviewed. In the article, the author addresses how such a community-led wide-area evacuation plan is indispensable for administrations' effective wide-area evacuation planning.

\section{NECESSITY OF FORMULATING COMMUNITY-LED WIDE-AREA EVACUATION PLAN}

\subsection{Community disaster management plan and wide-area evacuation}

Japan has established the Disaster Countermeasure Basic Act as a comprehensive and longterm national and regional disaster management plan for prefectural and municipal governments, implementing disaster management activities at each level.

However, immediately after the 2011 Great East Japan earthquake, many deeply recognized that disaster countermeasures after a large-scale wide-area disaster work well, especially with mutual cooperation through self-help, mutual help, and public help [8]. On the basis of lessons learned, in 2013, some provisions concerning self-help and mutual help were added to the Disaster Countermeasure Basic Act [7]. At that time, from the perspective of the local community's mutual help disaster management activity, a community disaster management plan was established. This involved voluntary disaster management activities conducted by residents and businesses (community residents, etc.) in certain municipal districts [8].

The 2015 Kanto and Tohoku heavy rains resulted in massive flooding of the Kinugawa River and $40 \mathrm{~km}^{2}$ or one-third of the area of Joso City in Ibaraki Prefecture, causing two human casualties. At the flood's height, more than 4,000 people were stranded and later rescued with helicopters and boats [9]. The Irie survey [10] indicated that the greatest number of evacuees $-35 \%$ - headed out of Joso City via car ( $89 \%$ of all related evacuation means). 
In terms of motivation, $41 \%$ of evacuees were "family and friends prompted". Moreover, most of those affected indicated that they remained indoors due to normality bias, believing that the heavy rain would not inundate or that moving was difficult "considering the elderly". The reason "neighbours are not evacuating" also rated high, accounting for $12 \%$ of survey responses [10].

Based on lessons from Joso City flooding due to the 2015 Kanto and Tohoku heavy rain disaster and Mabi-cho in Kurashiki City, Okayama Prefecture, due to the western Japan heavy rain disaster, a wide-area evacuation plan is necessary to facilitate early evacuation across municipal boundaries before an incoming disaster [9], [11]. Such a plan should prioritize support for persons needing evacuation help that requires municipal transportation to welfare facilities, along with evacuation support by the neighbourhood [12]. Hence, residents and the administration must work together to support those who cannot evacuate without assistance. To achieve a community's wide-area evacuation, residents must have the intention of evading and evacuating; a system is created that encourages them to do so, with encouragement not only from their families and friends but also their neighbours. The administration's role in wide-area evacuation is controlling traffic, providing guidance to enable evacuation, and securing vehicle evacuation routes. Particularly important is securing public shelters, including welfare facilities; therefore, prior coordination among municipalities is indispensable [12].

\subsection{Cooperation between community- and government-led wide-area evacuation plans}

The Cabinet Office of Japan has summarized the basic concept of wide-area evacuation from floods [13], created guidelines [14], and is promoting local governments' formulation of wide-area evacuation plans. Some government-led plans are ineffective, however. Kazo City, Saitama Prefecture, and Sakai Town in Ibaraki Prefecture, with the support of the Ministry of Land, Infrastructure, Transport and Tourism (MLIT) and prefectures, conducted surveys and research on wide-area evacuation [15] (for example, Sakai Town, Local Autonomy Research Organization, 2018) and formulated wide-area evacuation plans, adding them to their regional disaster management plans. At the time of typhoon No. 19 in 2019, both cities and towns conducted wide-area evacuation according to the plan. In Kazo City, however, the following problems were highlighted: the parking lot of the evacuation destination became full, the road became heavily congested, and the residents were confused due to a delay in issuing evacuation information [16].

In addition, Kazo City's bulletin (August 2020) reported that residents were surprised that the list of evacuation destinations outside the prefecture disappeared from the evacuation route map [17]. Even in Sakai Town, Ibaraki Prefecture, a line hundreds of meters long of residents evacuating by car formed at the evacuation center. Moreover, residents complained of anxiety because of the time it took to enter the shelter [18]. Finally, immediately after the town issued an evacuation order, residents began moving all at once, causing traffic congestion. These problems are considered to have arisen because residents' concrete evacuation behaviour was not sufficiently reflected in the plan. After that, Sakai Town increased the number of evacuation sites outside of town and negotiated with the city to secure four parking lots of the city's parks and temples where townspeople who evacuated by car could spend time [18].

In other words, if a wide-area evacuation plan is formulated under residents' initiative, the local government can consider evacuation support according to the actual situation. In government-led plans, however, residents often act according to their judgment while also following government instructions, causing a gap between response actions. Especially in 
large-scale and wide-area evacuation, top-down or government-led plans tend to be emphasized. However, it should go without saying that creating a bottom-up or communityled wide-area evacuation plan is important in district disaster prevention. Also important is enhancing the plan's effectiveness by coordinating mutual and public assistance.

\section{WIDE-AREA EVACUATION PLAN AND RISK COMMUNICATION AT THE RIVERSIDE DISTRICT}

\subsection{Outline of the Riverside District}

Fig. 1 illustrates an assumed inundation map of the Kofu Basin and the River-side District, which takes the name of the community of "Riverside Town" in Chuo City, Yamanashi Prefecture. Situated on the Kamanashi River's left bank, the Riverside District was once a water reservoir sandwiched between a dike and the river. After the Kamanashi River flooded in 1907, the Usuinuma swamp was formed. Reclamation of the swamp began in 1977, and residential construction has created the largest residential district in the Kofu basin, with nearly 1,400 households, 4,000 residents, and a potential population of 7,000. Residential land was first sold from the north area, represented by three residents' associations: the 1st Association of the North, the 2nd Association of the Central, and the 3rd Association of the South [7].

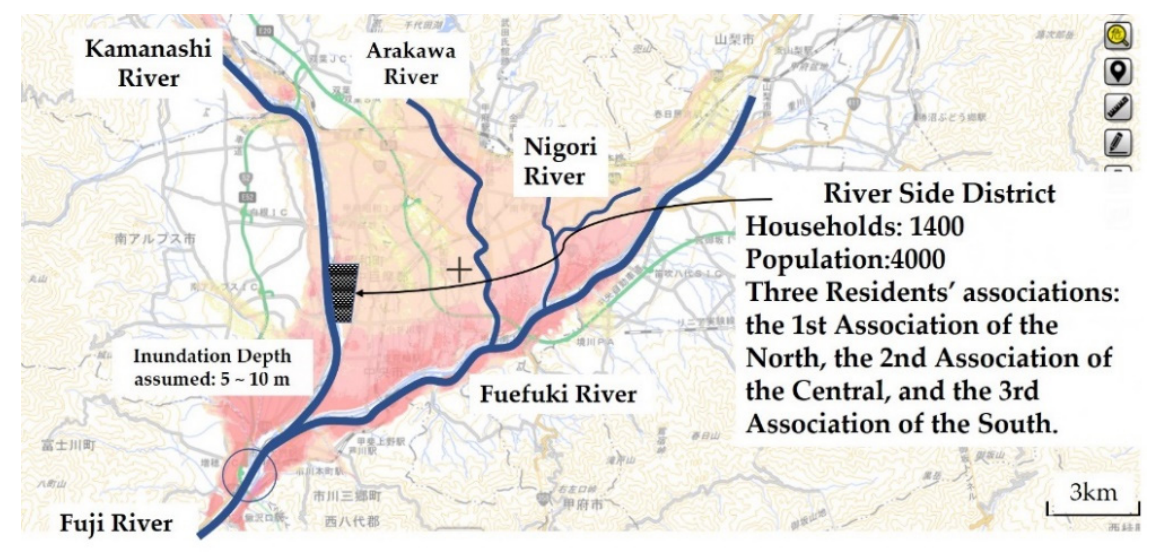

Figure 1: Assumed inundation map of the Kofu Basin and the location of the Riverside District.

\subsection{Risk communication for a wide-area evacuation plan}

To evacuate community residents, the author proposed implementation of a risk communication approach using the "creating Confidence, generating Awareness, enhancing Understanding, gaining Satisfaction, and motivating Enactment (CAUSE) model" proposed by Rowan [19], Rowan et al. [20] and Suzuki [21]. In the Riverside District, Chuo City, the author implemented these processes twice for wide-area evacuation plan development. The first process covered the 3rd Residents' Association evacuation plan, and the second expanded it to the entire Riverside District. Consequently, in May 2019, the whole district's (1st through 3rd residents' associations with 1,400 households and 4,000 people) community 
disaster management plan was formulated as a wide-area evacuation plan at the final stage of "Enactment" (see Fig. 2 for a schematic) [22].

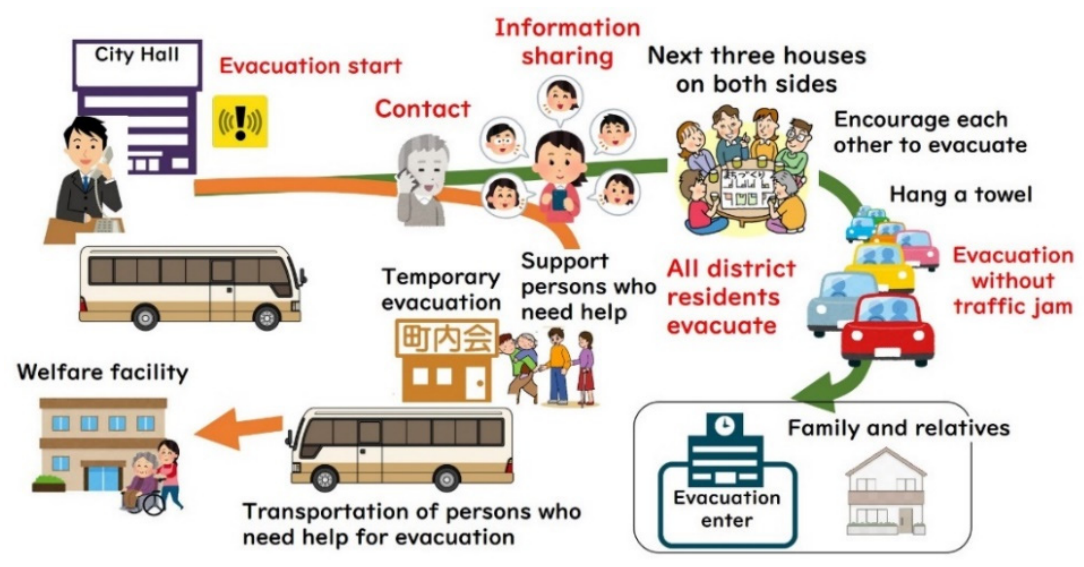

Figure 2: Schematic representation of the Riverside District's evacuation plan [22].

Fig. 3 is the "My Timeline" of evacuation (preparation and) behaviour distributed to each household, but when the authors presented this timeline in 10 stages, residents added some ideas to create the timeline shown in Fig. 3. Finally, the timeline was printed on B5-size glossy paper in black and red two-colour printing and distributed to all households. In 2018, the timeline had a red border, but in 2019, a blue one. The 2020 version is described below. The timeline is now published annually, and residents update such information as evacuation sites.

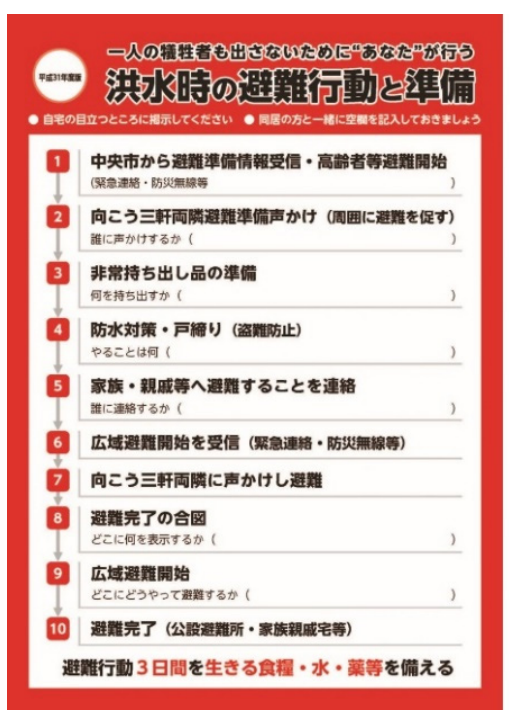

\footnotetext{
1. Receive evacuation preparation information and begin evacuating people needing help

2. Encourage each other to evacuate (call to the next three houses on both sides)

3. Prepare emergency items

4. Take waterproof measures

5. Inform family and friends of evacuation

6. Receive wide area evacuation start

7. Call each other to begin evacuation

8. Signal evacuation completion

9. Start wide-area evacuation

10. Complete evacuation
}

Figure 3: "My Timeline" of evacuation preparation and behaviour distributed to each household. 
Through three years of risk communication activities, local residents became well aware of and understood the community's flood risk, found a solution on their own, accepted proposals for wide-area evacuation, and finally formulated the community disaster management plan for wide-area evacuation.

\section{RISK COMMUNICATION TO CLARIFY EACH STAKEHOLDER'S ROLE IN WIDE-AREA EVACUATION}

\subsection{BECAUSE model}

The author developed the BECAUSE model as a training process that fosters local government officials' ability to communicate with organizations inside and outside agencies to facilitate disaster response. Therefore, the meaning of each CAUSE steps in BECAUSE differed somewhat from Rawan's CAUSE model. Moreover, the S in BECAUSE means "Satisfaction", which includes the stage of local government staff proposing a "Solution" on their own or with a new method of disaster response [23]. In addition, BE refers to the stage of preparation for training in which an environment must be built where local government staff can participate; $\mathrm{BE}$ is therefore a stage for gaining familiarity with the local administration's governor, mayor, and senior staff. In 2013, the BECAUSE model was applied to construction of a regional cooperation system for wide-area evacuation, having been classified into three sections: a disaster-affected municipality; neighbouring municipalities supporting it; and a supporting organization of disaster management and construction departments of the prefectural government, prefectural police headquarters, and river administrators of MLIT. Later, a disaster response exercise was conducted as the final step, E, of the BECAUSE model to verify the constructed regional cooperation system's effectiveness [24]. However, wide-area evacuation at this time involved residents from one municipality evacuating to another nearby municipality.

\subsection{Each stakeholder's role in wide-area evacuation}

The author individually interviewed and exchanged opinions with the mayor of Chuo City, the director of the Disaster Management Bureau, Yamanashi Prefecture, and the director of the Kofu Regional River and Road Office, MLIT. The most serious problem is that people do not evacuate even when an evacuation information is issued. Furthermore, the author explained that such stakeholders as local and national governments should have a role in wide-area evacuation, as summarized in Fig. 4, if all basin residents are to implement the plan as the risk communication stage of Understanding and Satisfaction [25].

Risk communication's purposes are for residents of Chuo City, Yamanashi Prefecture, and MLIT to declare the role they should play in the Kofu basin's large-scale flood evacuation and to recognize one another's roles. Essentially, citizens should share wide-area evacuation plans as much as possible. Apart from the wide-area evacuation plan, various nonstructural measures such as a legal-based system and structural measures such as raising residential lands, roads, and high-rise buildings as water-proofing measures might be future targets to improve the Kofu basin's flood resilience.

On 25 December 2018, the author held a disaster management symposium and planned "Make use of lessons learned from Mabi-cho for wide-area evacuation in the Kofu basin" as a panel discussion of each stakeholder's role. In the panel discussion, both panelists and citizens should discuss appropriate actions. Besides the author, the panel included the 


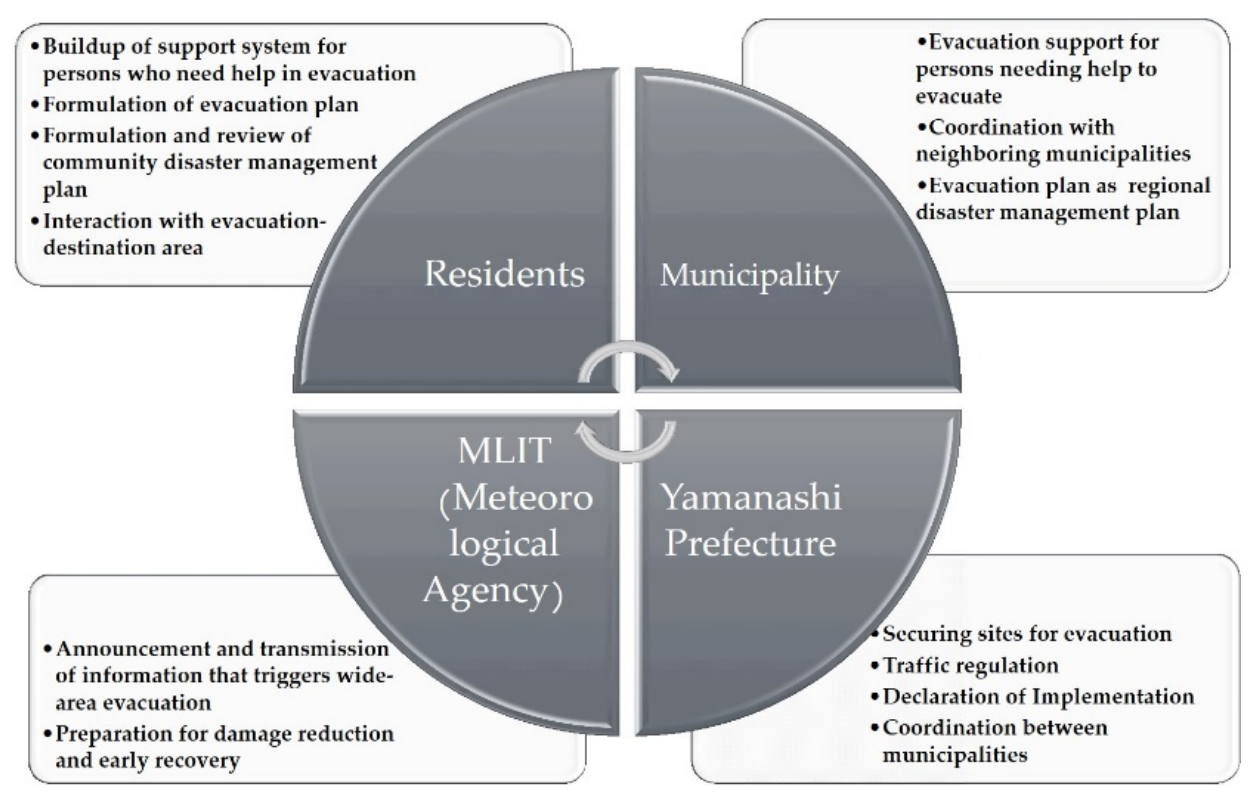

Figure 4: Roles of Ministry of Land, Infrastructure, Transport and Tourism (MLIT), prefectures, municipalities, and residents in wide-area evacuation.

chairman of the Riverside District's 3rd Residents' Association, the mayor of Chuo City, the director of the Disaster Management Bureau in Yamanashi Prefecture, and the director of the Kofu Regional River and Road Office of the MLIT. The chairman of the Riverside District 3rd Residents' Association stated that to evacuate a wide area without casualties, evacuation support is necessary for those who need help during evacuation, and so is development of an wide-area evacuation plan by the 3rd Residents' Association for the entire Riverside District. Additionally, the chairman declared that in the next stage, Chuo City should develop such a plan for the entire city and further requested that the city issue early evacuation information for citizens to initiate the evacuation plan and secure evacuation destinations.

The mayor of Chuo City stated the essence of assessing transportation means for evacuation, given the wide-scale plan. He further mentioned that the city was initiating an interregional evacuation study in cooperation with the neighbouring Showa Town, supported by MLIT, within the framework of the Disaster Mitigation Council in the Fuji River basin. Moreover, the mayor expressed interest in continuous assessment of the wide-area evacuation plan with cooperation of Yamanashi Prefecture and MLIT.

The director of the Disaster Prevention Bureau, Yamanashi Prefecture stated that the prefecture's role is actively to advise and support municipalities' development of an evacuation plan, establish a forum for consultation among related organizations, and ensure consistency among municipalities' implementation of evacuation plans. Moreover, the director stressed the prefecture's responsibility to inform residents of the wide-area evacuation plan and implement an evacuation exercise accordingly.

The director of Kofu Regional River and Road Office stated that the office's role is to advise Yamanashi Prefecture on criteria for wide-area evacuation. Therefore, criteria that trigger wide-area evacuation are to be decided at this examination stage. In the event of a flood, MLIT should provide information when such criteria are reached. 


\section{MEASURES AGAINST COVID-19 AND WIDE-AREA EVACUATION DRILLS IN THE RIVERSIDE DISTRICT}

\subsection{Wide-area evacuation in a safe parking lot in neighbouring municipalities}

In the wide-area evacuation plan, evacuation itself does not mean "sheltering" at an evacuation center but escaping dangerous places and saving lives. In the event of heavy rain when the Riverside District conducts wide-area evacuation, neighbouring municipalities should be evacuation destinations. Therefore, designated evacuation centers in areas not directly affected by heavy rain disasters are accustomed to accepting evacuees, so neighbouring municipalities cannot be expected to open designated evacuation centers for the Riverside District. Therefore, the district's wide-area evacuation plan requires that residents secure themselves with relatives and in acquaintances' homes and hotels, etc. as evacuation destinations. Residents who cannot do so may choose to evacuate in a car and park on a hill in a neighbouring municipality. The author examined a parking lot that is a candidate for an evacuation site in nearby Nirasaki City, based on the following conditions:

1. Large parking lot or parking space (20 cars or more);

2. Existence of facilities with water and toilets;

3. Existence of facilities where elderly people can rest;

4. Wide access road from public roads to facilities;

5. Existence of residents' association (community residents) that can support evacuees.

The fifth condition above is necessary because evacuees who do not know the community cannot well deal with unforeseen problems occur and they need help. Yamamura also emphasizes the need for cooperation with neighbouring residents' associations while evacuees stay in their cars [25].

Examination of such places on the map and in the field survey revealed 23 facilities: public halls, welfare facilities, closed elementary schools, municipal facilities/parks, and parking lots of private companies with space for 700-800 cars. Thus, if approximately half of the households in the Riverside District can secure evacuation destinations with relatives and in acquaintances' homes and hotels, the remaining households can evacuate in their cars to a safe parking lot. Elderly people who cannot secure shelter or travel to a parking lot on their own will be asked to register as residents who need assistance and be evacuated to the welfare center by city bus or car with their neighbours' support.

\subsection{Wide-area evacuation action considering measures against COVID-19 infection}

At the 15 July 2020 district leaders' meeting, the Riverside District representative proposed the third-year (2020) version of "Evacuation Action and Preparation in the Event of a Flood Disaster", which is the My Timeline scheduled for annual updating. The $2020 \mathrm{My}$ Timeline included measures to prevent COVID-19 infection. In addition, distributed evacuation by each household was added while responding to the five levels of alert for heavy rain disasters, corresponding to municipalities' evacuation information.

Therefore, preparation (preparedness), evacuation behaviour (evacuation), and staying at an evacuation center (sheltering) are mixed. Furthermore, coronavirus infection control was added, so the most important wide-area evacuation is actually inconspicuous. Since the district representative is quite familiar with water disaster prevention, he attempted to squeeze every action into the timeline: advance preparation, wide-area evacuation 24 hours before a disaster, and evacuation of residents late for the beginning of wide-area evacuation. 
As a result, the My Timeline was somewhat lacking in cohesion and organization. Some leaders at the meeting commented that the timeline should be simpler and that residents could not write on it; even so, a concrete amendment was not finalized.

Therefore, the author proposed to examine the timeline and to present an amended one at a later date; this proposal was approved. In the amended timeline, the preparatory stage was first described and next the timeline for wide-area evacuation. After describing how to ensure emergency safety in case of being late for wide-area evacuation, actions prior to beginning evacuation and those during evacuation implementation/completion are described separately. For the Riverside District, the most notable evacuation behaviour is to call to three houses on either side before beginning evacuation. Finally, the timeline's evacuation implementation/ completion column describes COVID-19 countermeasures for evacuation sites.

At the next board meeting, leaders welcomed and approved the author's amended timeline. By August 19, the My Timeline for "evacuation action and preparation" was printed on a green background (Fig. 5) and presented to the board prior to distribution to all district households.

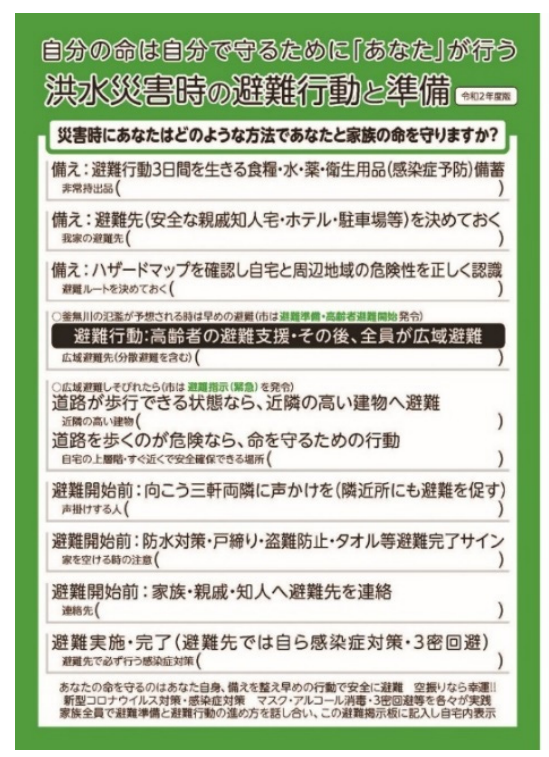

Evacuation Action and Preparation in the Event of a Flood Disaster

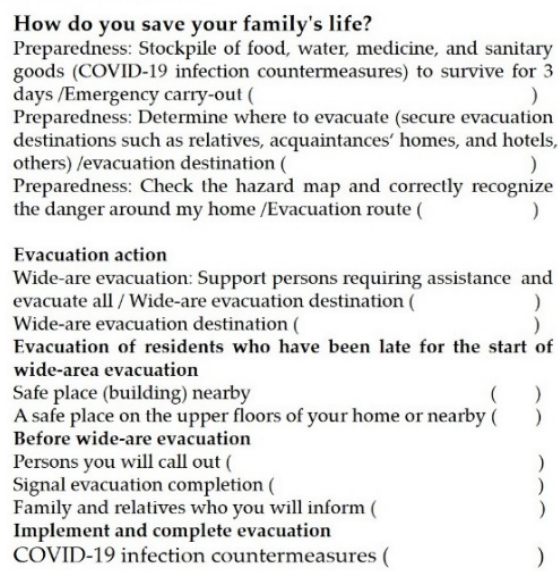

Figure 5: 2020 My Timeline for evacuation behaviour and preparation.

\subsection{Cooperation from Chuo City and Yamanashi Prefecture}

For the Riverside District's wide-area evacuation, evacuation by bus of those requiring assistance was vital. Therefore, Chuo City positioned this wide-area evacuation drill as training for transferring people requiring assistance. The city requested cooperation from Santo Kotsu Co. Ltd., and in March 2020, Chuo City signed an agreement that the company's bus could be used for evacuation. Chuo City arranged minitrucks, tents, questionnaires, rubbing alcohol, chairs, cardboard beds, portable toilets, etc., along with buses for transporting people needing evacuation support. Chuo City's Crisis Management Division attended the Riverside District's board of directors meeting to share information from the training's preparatory stage. 
The Riverside District's wide-area plan assumes evacuation to the hills of Nirasaki City, and in the 2020 evacuation drill, residents' association leaders planned to evacuate to Nirasaki City. However, Nirasaki City refused to provide an evacuation site it had once offered because it could not obtain nearby residents' cooperation due to the COVID-19 pandemic. In response, Chuo City consulted with the Disaster Management Bureau of Yamanashi Prefecture, which proposed the parking lots of two prefectural facilities as alternatives. From the two candidate sites, the Riverside District selected the Prefectural Clean Energy Center in Kai City located on a hill between Nirasaki City and Chuo City (Fig. 6). Since the center's toilet facilities can be rented along with the parking lot, conducting wide-area evacuation drills has become possible. Yamanashi Prefecture not only cooperated by providing evacuation shelters but also dispatched two staff members on the day of the drill.

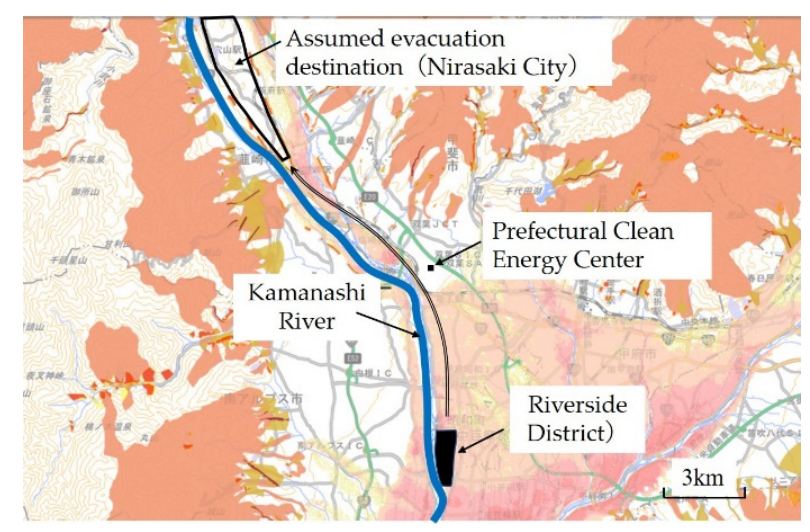

Figure 6: Positional relationship among the Riverside District, the Prefectural Clean Energy Center, and the hills of Nirasaki City.

On the day of the drill, Santo Kotsu Co., Ltd. provided two buses. In the district, two residents needing evacuation assistance and four supporters had been selected in advance, and these six residents experienced bus boarding training. The drill provided Santo Kotsu an opportunity to notice points to consider when transporting people requiring evacuation assistance (Fig. 7(a)). As a measure to prevent COVID-19 infection, each inhabitant wore a self-provided mask, disinfected the hands with alcohol, and maintained an interval of $1.5 \mathrm{~m}$. Having provided 51 of alcohol for hand disinfection (given to participants in small containers) and a thermometer, district officials took participants' temperatures. Fig. 7(b) shows the training led by residents.

\section{RISK COMMUNICATION FOR FORMULATION OF WIDE-AREA EVACUATION PLANS FOR YAMANASHI PREFECTURE AND CHUO CITY}

\subsection{Meeting between Riverside District and Chuo City}

Riverside District community leaders visited Chuo City's mayor and deputy mayor to thank them for the city's cooperation in wide-area evacuation drills (Fig. 8). In addition, drills' results were summarized and reported. Chuo City was also requested to formulate a wide- 


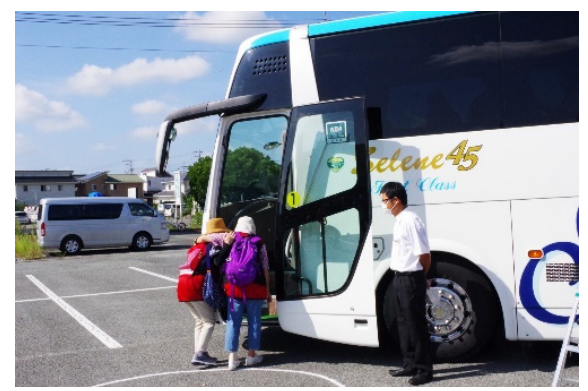

(a)

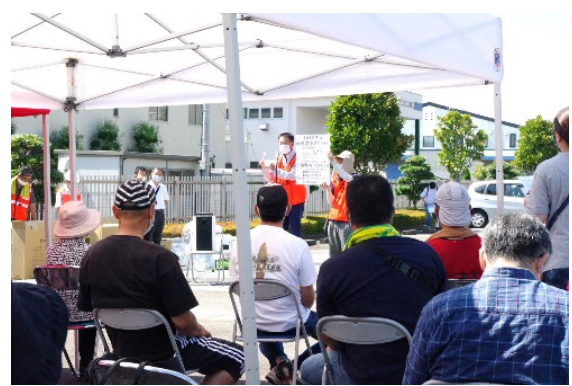

(b)

Figure 7: Photographs of wide-area evacuation drills' implementation. (a) A resident needing assistance is helped to board a bus; and (b) Community leaders explain training content.

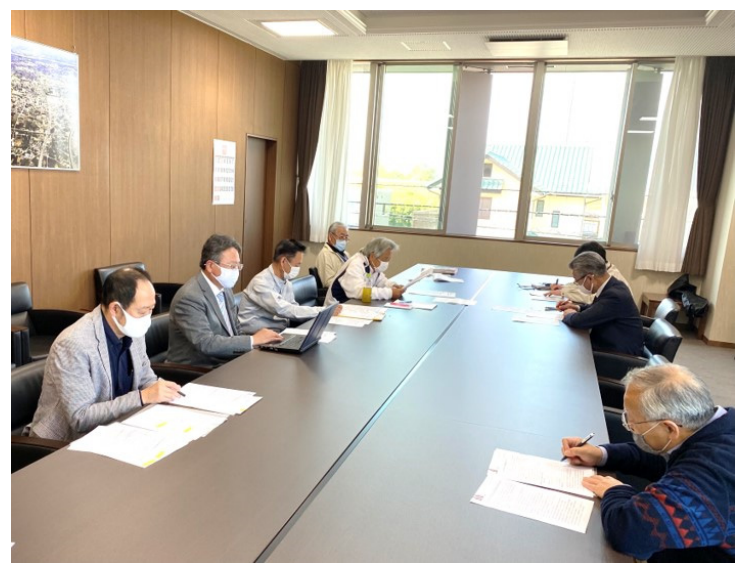

Figure 8: Meeting between community residents and the city at Chuo City Hall.

area evacuation plan, secure wide-area evacuation destinations for the district at an early stage, and develop a community disaster management plan for other areas.

Disaster management drills sponsored by the city have been held close to September 1st every year, the day the Great Kanto Earthquake struck in 1923. However, disaster management drills for flood control are more effective around June, before the flood season. In addition, holding a disaster management drill in September, a period of high temperatures and high humidity, might harm participating residents' health. For these reasons, Riverside District community leaders have offered to hold a disaster drill for Chuo City the following year in June, and Chuo City promised to respond to this offer in early December. At a later date, the drill scheduled for June was postponed due to lack of preparation, but the city's cooperative attitude was recognized.

The author also attended this meeting and advised Chuo City on the following three points:

1. Resume negotiations with Nirasaki City on acceptance of evacuees. 
2. Visit Kazo City, Saitama Prefecture to investigate the actual situation of the wide-area evacuation from Kazo City during typhoon No. 19 in 2019. Reports have indicated that typhoon evacuation exposed the disadvantage of wide-area evacuation formulated by the government as a back-up for the city. As a result, Kazo City is reportedly putting a brake on wide-area evacuation. Since it seems that wide-area evacuation's effectiveness cannot be guaranteed without bottom-up efforts by the Riverside District, the author proposed that Chuo City officials visit Kazo City to interview city officials and residents who conducted wide-area evacuation.

3. Expand formulation of community disaster management plans for wide-area evacuation and begin formulating wide-area evacuation plans for the city. It has already been confirmed that the MLIT and Yamanashi Prefecture are ready to support formulation of a wide-area evacuation plan for Chuo City.

\subsection{Risk communication with stakeholders}

As previously mentioned, the author exchanged opinions on each organization's role in conducting wide-area evacuation with the Kofu Regional River and Road Office of the MLIT that manages the Kamanashi River, Yamanashi Prefecture, and Chuo City. As a result, a symposium was held with representatives of these organizations, residents in the Riverside District, and the author as an expert in disaster management, to clarify each stakeholder's role [25].

To ensure the effectiveness of the Riverside District and Chuo City's wide-area evacuation, the plan should specify each institution's role as agreed upon during the symposium. Although Chuo City's mayor remains in office, since the symposium, personnel shifts have brought new directors to the Kofu Regional River and Road Office of the MLIT and to the Disaster Management Bureau of Yamanashi Prefecture. Therefore, the author exchanged opinions about Chuo City's wide-area evacuation plan with the Kofu Regional River and Road Office of the MLIT and confirmed that the office understands its role and is ready to support the plan as much as possible. In fact, the MLIT is strengthening its stance of actively supporting formulation of regional disaster management plans for municipalities against flooding by rivers under the ministry's control. The author also exchanged opinions with the Disaster Management Bureau of Yamanashi Prefecture, which is also preparing to formulate a wide-area evacuation plan and therefore promised to provide as much support as possible to improve mutual plans' consistency.

After confirming these organizations' intentions, the author urged Chuo City to consult with the Kofu Regional River and Road Office and Yamanashi Prefecture to confirm the content of support and then prepare for formulation of a wide-area evacuation plan. In response, Chuo City visited the Kofu Regional River and Road Office of the MLIT and Yamanashi Prefecture to discuss support for formulating a wide-area evacuation plan. After that, Chuo City informed the author that it would start formulating a wide-area evacuation plan in 2021.

\section{CONCLUDING REMARKS}

In the Riverside District of Chuo City, which has a high risk of flooding, a community disaster management plan for wide-area evacuation was formulated as a result of support applied by the author through risk communication. In this district, an evacuation support system for people needing evacuation assistance has been established, and wide-area evacuation actions for each household have been summarized in a timeline. However, because this evacuation plan contains measures dependent on administrative agencies - 
municipalities, prefectures, and central ministries - for evacuating people requiring assistance, selection of evacuation sites, and traffic control of evacuation routes, it needs to be consistent with these agencies' wide-area evacuation plan.

When a community-led plan is formulated in this way, the municipality can formulate a concrete, highly effective wide-area evacuation plan to support residents' evacuation behaviour. In fact, Chuo City has decided to formulate a wide-area evacuation plan in 2021. Similarly, to enhance the effectiveness of municipalities' wide-area evacuation plans, issues that prefecture should address will be clarified, and the prefecture's wide-area evacuation plan's effectiveness will also increase. Taking this opportunity, Yamanashi Prefecture is expected to begin formulating a plan for the entire Kofu basin - not government-led, topdown but a highly effective wide-area evacuation plan that combines bottom-up and topdown.

\section{ACKNOWLEDGEMENTS}

The success of risk communication reported in this study is largely due to the great efforts of Mr. Hosokawa and other community leaders of the Riverside District and the active efforts of the residents of the district. I express my sense of gratitude to them all of the Riverside District. I would like to express our deepest gratitude to Mr. Kaneko, Deputy Director of the Kofu River National Highway Office for his great cooperation in risk communication with Yamanashi Prefecture and Chuo City based on the promotion measures of the basin flood control project of the Ministry of Land, Infrastructure, Transport and Tourism.

\section{REFERENCES}

[1] Japan Meteorological Agency (JMA), Number of typhoons landing. https://www.data.jma.go.jp/fcd/yoho/typhoon/statistics/landing/landing.html. Accessed on: 10 Sep. 2021.

[2] Japan Institute of Construction Engineering (JICE), Flood control project implementation system in European countries: Flood control project plan based on climate change. JICE Report, 111001, 2011. (In Japanese.)

[3] Suzuki, T., Legal systems. Disaster Engineering, Riko Tosho: Tokyo, pp. 287-299, 2019. (In Japanese.)

[4] Suzuki, T., Building up a common recognition of city development in the southern part of Kofu Basin under the initiative of knowledge brokers with the cooperation of experts. Sustainability, 12(16), p. 6316, 2020. https://doi.org/10.3390/su1216631.

[5] Suzuki, T., Risk communication process applicable to make the Kofu Basin resilient to flood. KASEN(River), 874, pp. 23-27, 2019. (In Japanese.)

[6] Suzuki, T., Watanabe, T. \& Okuyama, S., Community disaster management plan to implement extensive evacuation without a single victim against flooding. Journal of Community Disaster Management Society (C-Bosai), 13, pp. 35-50, 2018. (In Japanese.)

[7] Suzuki, T., Risk communication in order to facilitate community resilience against a large-scale flood. WIT Transaction on The Built Environment Disaster Management and Human Health Risk VI, vol. 190, WIT Press: Southampton and Boston, pp. 145155, 2019.

[8] Murosaki, Y. \& Tominaga, Y., Chapter 5. Mutual-Help in Creation of People to Confront Disasters, Minerva Shobo: Kyoto, pp. 77-86, 2018. (In Japanese.)

[9] Joso City Flood Control Verification Committee, Verification report on disaster response to flood in Joso City due to Kinugawa River flood, 2015. (In Japanese.) 
[10] Irie, S., Levee collapse of the Kinu River: How did Joso city residents evacuate? From a survey on residents' disaster information awareness and evacuation behaviour at the 2015 heavy rainfall in Kanto and Tohoku regions. The NHK Monthly Report on Broadcast Research, 66(8), pp. 36-65, 2016. (In Japanese.)

[11] Verification Committee of the July 2018 Heavy Rain disaster, Okayama Prefecture, Verification Report on the July 2018 flood disaster. http://www.pref.okayama.jp/ uploaded/life/601705_5031910_misc.pdf. Accessed on: 10 Sep. 2019.

[12] Suzuki, T., System creation and information sharing environment aiming for wide area cooperation at the time of large-scale disaster. City Planning Review, 64(6), pp. 6467, 2015. (In Japanese.)

[13] Cabinet Office of Japan, Guidelines for disaster information, May 2021. http://www.bousai.go.jp/oukyu/hinanjouhou/r3_hinanjouhou_guideline/pdf/hinan guideline.pdf. Accessed on :10 Sep. 2021.

[14] Cabinet Office of Japan, Basic way of thinking about wide area evacuation from flood damage, May 2021. http://www.bousai.go.jp/fusuigai/suigai_kouikihinan/pdf/ kangaekata.pdf. Accessed on: 10 Sep. 2021.

[15] Sakai Town \& Local Government Research Organization, Survey and research on damage mitigation measures and wide-area evacuation action plan creation based on heavy rain disasters, 2018.

[16] Mainichi Newspaper, One month from wide-area evacuation due to the typhoon No. 19, 2019. https://mainichi.jp/articles/20191112/ddl/k11/040/118000c. Accessed on: 10 Sep. 2021.

[17] Mainichi Newspaper, Wide-area evacuation in Kazo City, Saitama. https://mainichi.jp/ articles/20201010/k00/00m/040/038000c. Accessed on: 10 Sep. 2021.

[18] Asahi Newspaper, Search for wide-area evacuation, Sakai Town, Ibaraki. https://www.asahi.com/articles/ASNC97VFWNBDUJHB00S.html. Accessed on: 10 Sep. 2021.

[19] Rowan, K., Why rules for risk communication are not enough: A problem-solving approach to risk communication. Risk Analysis, 14(3), pp. 365-374, 1994.

[20] Rowan, K., Botan, C.H., Kreps, G.L., Samoilenko, S. \& Farnsworth, K., Risk communication education for local emergency managers: Using the CAUSE model for research, education, and outreach. Handbook of Risk and Crisis Communication, Taylor \& Francis: London, pp. 168-191, 2009.

[21] Suzuki, T., Wisdom, Technique and Mechanism to Protect Life from Great Disaster, Shizuoka Academic Publishing: Shizuoka, pp. 154-196, 2014. (In Japanese.)

[22] Suzuki, T. Risk communication in the riverside district of Chuo City, Yamanashi Prefecture. Journal of Community Disaster Management Society (C-Bosai), 19, pp. 58-70, 2020. (In Japanese.)

[23] Suzuki, T. \& Uno, S., Development of disaster response management system with inter-organizational coordination. Journal of Disaster Information Studies, 10, pp. 122-133, 2012. (In Japanese.)

[24] Suzuki, T., Hada, Y. \& Miyamoto, T., Application of the BECAUSE model to establishment of a collaboration system with relevant administrative agencies for regional evacuation due to large river flooding capability and training process of its introduction. Journal of Disaster Information Studies, 14, pp. 105-115, 2016. (In Japanese.)

[25] Suzuk, T., Watanabe T. \& Okuyama, S., Facilitating risk communication for wide-area evacuation during large-scale floods. International Journal of Environmental Research and Public Health, 16, p. 2466, 2019. DOI: 10.3390/ijerph16142466. 
Disaster Management and Human Health Risk VII 165

[26] Yamamura, T., Practical Decentralized Evacuation and Shelter Management: Infectious Diseases X Large-scale Disasters, Gyosei: Tokyo, pp. 190-204, 2020. (In Japanese.) 